\title{
Study of some aspects of refining process physics of large-sized details precision surfaces
}

\author{
Viktor Vodzianskiy ${ }^{1}$, Viktor Artiukh ${ }^{2}$, , Sergey Kargin ${ }^{1}$, and Anzhelika Borisova ${ }^{3}$ \\ ${ }^{1}$ Pryazovskyi State Technical University, Universytetska str.7, 87500, Mariupol, Ukraine \\ ${ }^{2}$ Peter the Great St.Petersburg Polytechnic University, Polytechnicheskaya str. 29, 195251, \\ St. Petersburg, Russia \\ ${ }^{3}$ Moscow State University of Civil Engineering, 129337, 26, Yaroslavskoe Shosse, Moscow, Russia
}

\begin{abstract}
The paper presents experimental studies on physical and chemical processes that occur as a result of refining by 'GOI' paste (description in CIS countries, it states for State Optical Institute) largesized precision details made from non-ferrous metals. Number of hypotheses expressed by number of scientists is compared. Their essence has been revealed and a hypothesis has been adopted and confirmed by corresponding profilograms and photographs. It is most relevant to process of refining by 'GOI' paste of precision contacting inserts made from nonferrous metals. This is very important for agricultural engineering.
\end{abstract}

\section{Introduction}

\subsection{Formulation of task}

Preliminary laboratory studies conducted in department 'Mechanical Engineering Technology' of State Higher Education Institution 'Pryazovskyi State Technical University' and department 'Mechanics and Control Processes' of Federal State Autonomous Higher Education Institution 'Peter the Great St. Petersburg Polytechnic University' related with development of technology for revamp of large-sized isolation valves flat precision surfaces made from non-ferrous metals showed that in conditions of operating plant their repair is possible and it leads to significant reduction of costs compared to costs related with their replacement by new ones. To ensure stability of revamp process it is necessary to conduct series of studies to study issues that may arise when introducing proposed technology to production environment in order to obtain stable processing parameters (these are physical, chemical processes that occur when details are finished by refinement).

Analysis of recent research and publications. Considering worn flat precision surfaces of inserts made from non-ferrous metals installed in large-sized details of isolation valves (refer to fig. 1), it was found that for their full revamp sufficiently developed repair process should be carried out in three stages [1-6]:

- operation 1 is preliminary processing (fine turning or fine boring);

* Corresponding author: artiukh@mail.ru 
- operation 2 is preliminary refining (roughing);

- operation 3 is final refining (finishing).

When performing the first operation (machining) of brass precision inserts (LS 59.1 brass, description in CIS countries, it states for material with composition in which there are $57 . .60 \%$ of $\mathrm{Cu}$ and $0.8 \ldots 1.9 \%$ of $\mathrm{Pb}$ ) located around details circumference and being flat contact surfaces in housings and discs which provide necessary tightness of isolation valve assembly increase in tensile stresses within depth of $10 \ldots 15 \mu \mathrm{m}$ was observed with partial deformation of crystal lattice which is proved by studies [7-11] but these defects can be corrected by subsequent refinement. At this stage defects of operational wear on contacting surfaces of the details are removed and their flatness equal up to $10 \mu \mathrm{m}$ (which largely depends on geometric accuracy of used machine tool) and surface roughness $\mathrm{R}_{\mathrm{a}}=1.6 \ldots 0.8 \mu \mathrm{m}$ are provided. With this technology further processing of revamp of contacting surfaces is required which can be provided by additional refining operations in order to:

- formation of compression stress in surface layer;

- obtaining tolerance of flatness equal up to $1 . . .2 \mu \mathrm{m}$ and surface roughness $\mathrm{R}_{\mathrm{a}}<0.05 \mu \mathrm{m}$.

Considering that physical and chemical processes that occur during cutting by blade tool have been studied and explained quite deeply [2]. They are not considered and analyzed in this paper since this operation is preliminary and prepares surfaces for further processing by refining methods.
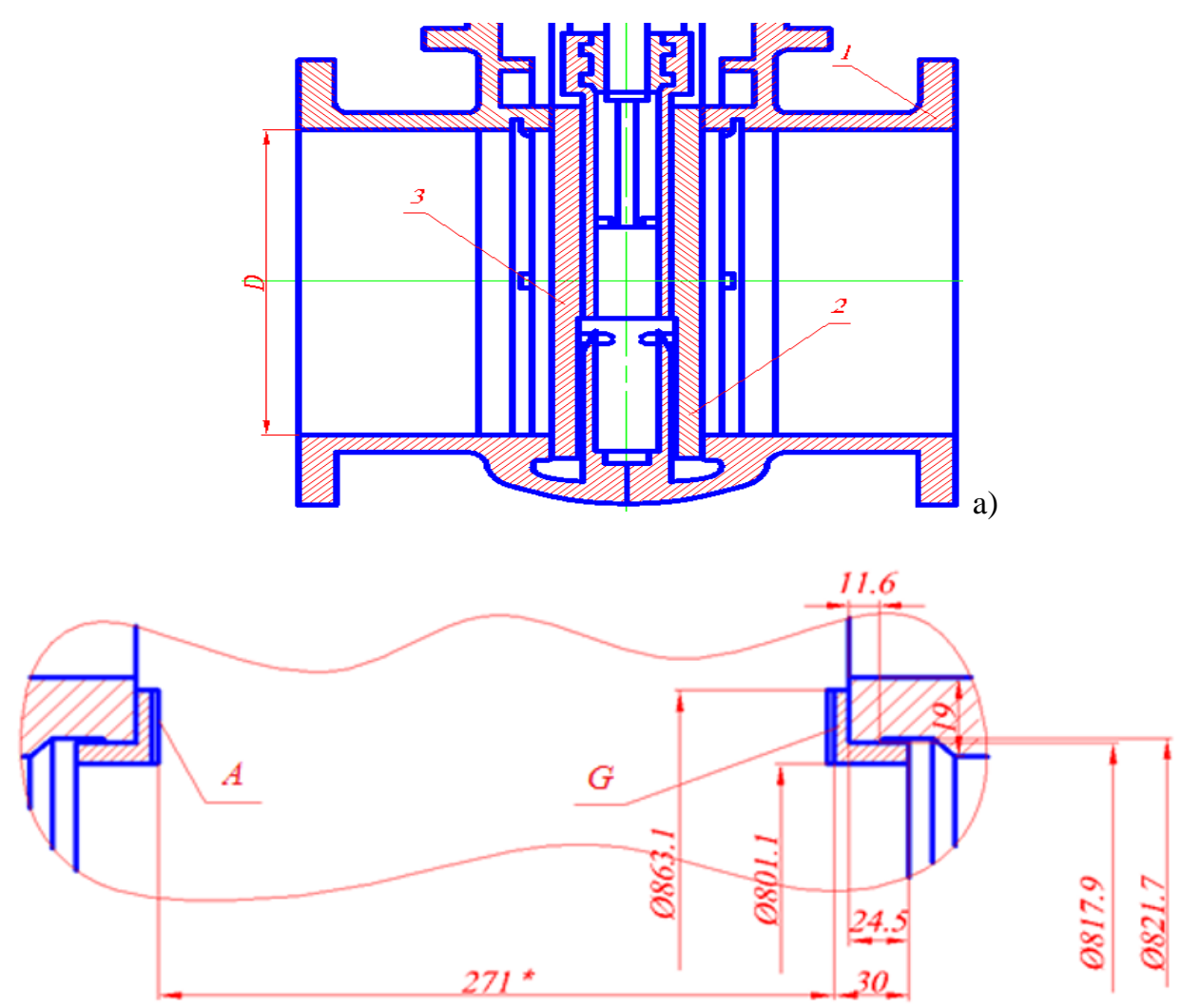

b)

Fig. 1. Pinch valve and frame contact surfaces are to be grinded smoothly: a) pinch valve design: 1 is frame; 2 is right disc; 3 is left disc. b) surfaces A and $G$ are to be grinded smoothly. 
More complex and insufficiently studied task is identification of physical and chemical processes that occur during refining operations that are finishing ones. At present, there is no single explanation for all processes that occur when refining tool comes into contact with processed detail. In this regard, there is a number of theories that with some approximation explains ongoing contact processes between cutting tool and detail when performing refining operations. Basic theories that with some degree explain processes that occur during refining are considered below.

One of these theories [12-14] draws analogy between grinding and refining processes, i.e. cutting chips on metal surface with harder abrasive grains; while crystal structure of the surface layer of detail is subjected to rough destruction. Refining is more gentle process since abrasive grains in this case have finer fraction which leads to significant reduction in force effect of grains on processed surface. This conclusion is most likely untenable because there are studies on process of hardened steels with soft abrasive materials or obtaining of mirror surfaces of soft materials using hard abrasive grains.

The second theory [15-17] explains process of processing by abrasive grains as deformation in relation to processed surface, i.e. during processing only plastic redistribution of material in upper layers of the surface occurs due to 'whipped' protrusions filling roughness troughs. This conclusion is also doubtful because in this case mass of processed detail should not change but in fact it decreases.

The third theory [18-20] explains surfaces refining process by abrasive grains as purely thermal, i.e. due to friction of abrasive on the surface to be processed temperature of the surface layer increases significantly which makes the surface layer liquefy and due to the surface tension forces 'troughs' are filled with 'protrusions' forming smooth surface and instantly solidified layer. As a result, the surface layer becomes not crystalline but amorphous. This is doubtful because in some cases process of refining (polishing) is carried out with addition of cutting fluids (coolant).

The fourth theory is expressed by academician I.V. Grebenshchikov in whose opinion essence of phenomena occurring during refining is reduced to successive removal by soft abrasive grains (for example, 'GOI' paste which contains chromium oxide as an abrasive) which form a 'juvenile' surface on metal surface which instantly oxidizes forming film of oxides which are then again cut off by other grains. Thus, roughness peaks are gradually removed without rough abrasion. But then long duration of refining process is difficult to explain, although chemical effect on the surface layer of minerals included in 'GOI' paste is quite strong; at the same time, according to this theory it is rather difficult to explain polishing tree by alcoholic solution of wax. However, this theory is closest to explanation of the physical and chemical processes that occur during refinement. Metal surfaces are always coated with oxide film that forms almost instantly (for example, for oxide layer with thickness of around $14 \mathrm{~A}$ on brass it takes around $0.25 \mathrm{~s}$ ). Not only oxygen but also chlorine, iodine, sulfur react similarly quickly with clean surfaces of metals forming corresponding films. These films are easily torn off even by soft abrasive powders in particular chromium oxide. Feature of such films is ability to adsorb only small or crushed substances and hold them firmly. Thus, surfaces of grinding and refined metal coated with oxides adsorb stearic or oleic acid molecules, acidic parts of molecules being located at metal surface and fatty radicals coming out. Abrasive fine powder adsorbs the fatty parts of acid molecules covering the surfaces of metals as if they glue two surfaces together (processed and ground). Due to difference in speeds of detail movement and grinding the film covering the surface to be processed breaks primarily in all those places where grinding tool is close to the surface. Exposed metal surface due to influence of oxygen or another reagent is again instantly covered with film which again breaks with abrasive powder. Thus, roughness is gradually removed and smooth surface is obtained without breaking crystal lattice with compressive stress on the processed detail surface. 
Performed analysis of literary sources shows that not one of the theories explains the refinement process, i.e. it is complex and it must be considered taking into account impact on it of all possible factors that may affect processing process.

Purpose of this paper is to investigate number of factors that significantly affect the physics of refining process:

1. Chemical effect of 'GOI' paste components which are involved in the refinement;

2. Cutting with abrasive grains or grinding (dispersion) of the thinnest surface layer;

3. Plastic flow of the surface layer.

Statement of the main information. Authors of this paper investigated chemical effect of constituent components of 'GOI' paste which contains surfactants as well as influence of abrasive grains sizes on refining process. 'GOI' paste was chosen due to its technological advantages in comparison with other compositions of abrasive mixtures because it is not liquid, not oily but 'hard' and can be easily applied to the surface to be processed or on ground. This is very important in our case because processed surfaces on machine tool are located vertically relative to the tool due to its design and overall features. At the same time, it reliably transports abrasive grains to processed zone, has surfactant in its composition and after processing it is easily removed from the processed surface. Composition of used 'GOI' paste is shown in table 1.

Table 1. Compositions of used 'GOI' pastes.

\begin{tabular}{|c|c|c|c|c|c|c|c|c|c|}
\hline \multirow{2}{*}{ Group } & \multirow{2}{*}{$\begin{array}{l}\text { Paste } \\
\text { number }\end{array}$} & \multicolumn{7}{|c|}{ Content, \% } & \multirow{2}{*}{ 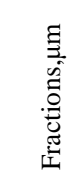 } \\
\hline & & $\begin{array}{l}\text { Chromi- } \\
\text { um oxide }\end{array}$ & $\begin{array}{c}\text { Stearic } \\
\text { acid }\end{array}$ & $\begin{array}{c}\text { Oleic } \\
\text { acid }\end{array}$ & Soda & $\begin{array}{c}\text { Kerose } \\
\text { ne }\end{array}$ & $\begin{array}{l}\text { Split } \\
\text { fat }\end{array}$ & Silica gel & \\
\hline Rough & $20-50$ & $81-86$ & $10-5$ & - & - & 2 & 5 & 2 & $20-50$ \\
\hline Medium & $10-15$ & $75-80$ & $11-6$ & - & - & 2 & 10 & 1.8 & $20-30$ \\
\hline Thin & $1-7$ & $70-75$ & $14-9$ & 2 & 0.2 & 2 & 10 & 1.8 & $6-10$ \\
\hline
\end{tabular}

Chemical effect of each of the components on course of refining process itself as well as its effect on the processed surface are considered below:

- stearic acid $\left(\mathrm{C}_{17} \mathrm{H}_{35} \mathrm{COOH}\right)$ provides high lubricity due to oxy groups which leads to formation of active oxygen radical, characterized by chemisorption and contributing to formation of cracks with sizes of $0.1 \ldots 0.2 \mu \mathrm{m}$ on surface of detail into which oxygen radicals penetrate softening the surface layer which contributes to its removal by abrasive grains, i.e. has high surface-active properties;

- oleic acid $\left(\mathrm{C}_{17} \mathrm{H}_{33} \mathrm{COOH}\right)$ is unsaturated monobasic carboxylic acid. It acts on surface similarly to saturated stearic acid enhancing its effect because it is able to go into it. It accelerates dissolution of metal oxides. Olein thins pasta making it more viscous, it has high chemical activity and accelerates dissolution of metal oxides. It is desirable to apply it in processing of metals which have more durable oxide film (aluminum, copper, brass);

- split fat is ester of triatomic alcohol-glycerol, stearic and oleic acids. It provides compound of abrasive in paste as well as lubrication in processing area;

- burning kerosene performs functions of paste solvent and facilitates its flushing from surface of detail after processing;

- soda is inputted only in finely dispersed (thin) paste compositions to improve their polishing properties;

- silica gel is used in paste to bind water. 
Below given conclusion can be made by analyzing effect of each of the pastes components on surface layer of metal to be processed during refining. All components except chromium oxide (abrasive component) contribute to occurrence of absorption and chemisorption processes when cutting by abrasive grain while contributing to formation of thin oxide films of $1.4 \mathrm{~nm}$ thick which are then easily broken by abrasive grains together with processed finely divided metal adsorbed in them and also contribute to appearance of microcracks with depth of $0.01 \ldots 0.02 \mu \mathrm{m}$ in metal. Preliminary experiments confirm this.

Relative speeds of processed surface and abrasive grains are small during refining. In addition, abrasive grains are located in malleable (elastic) environment, i.e. grains cannot cause deep scratches in contact with processed surface and cutting process (removal of metal) is carried out in gentle mode. This is facilitated by constant and continuous change in grain size (crushing) as well as its geometric parameters (blunting). In this regard, number of contact 'cutting points' is constantly increasing that leads to fact that cutting process almost stops after a certain time. In addition to plastic deformation that occurs during cutting (cutting process is always deformational) plastic deformation is added that arises from heat which arises during friction. Thus, parts of micro-roughness remaining from previous process soften during refining and metal spreads along surface to be processed. Moreover, at the beginning of the process cutting factor is of greater importance and factors of metal plastic flow are of greater importance at the end of it, i.e. smoothing the surface.
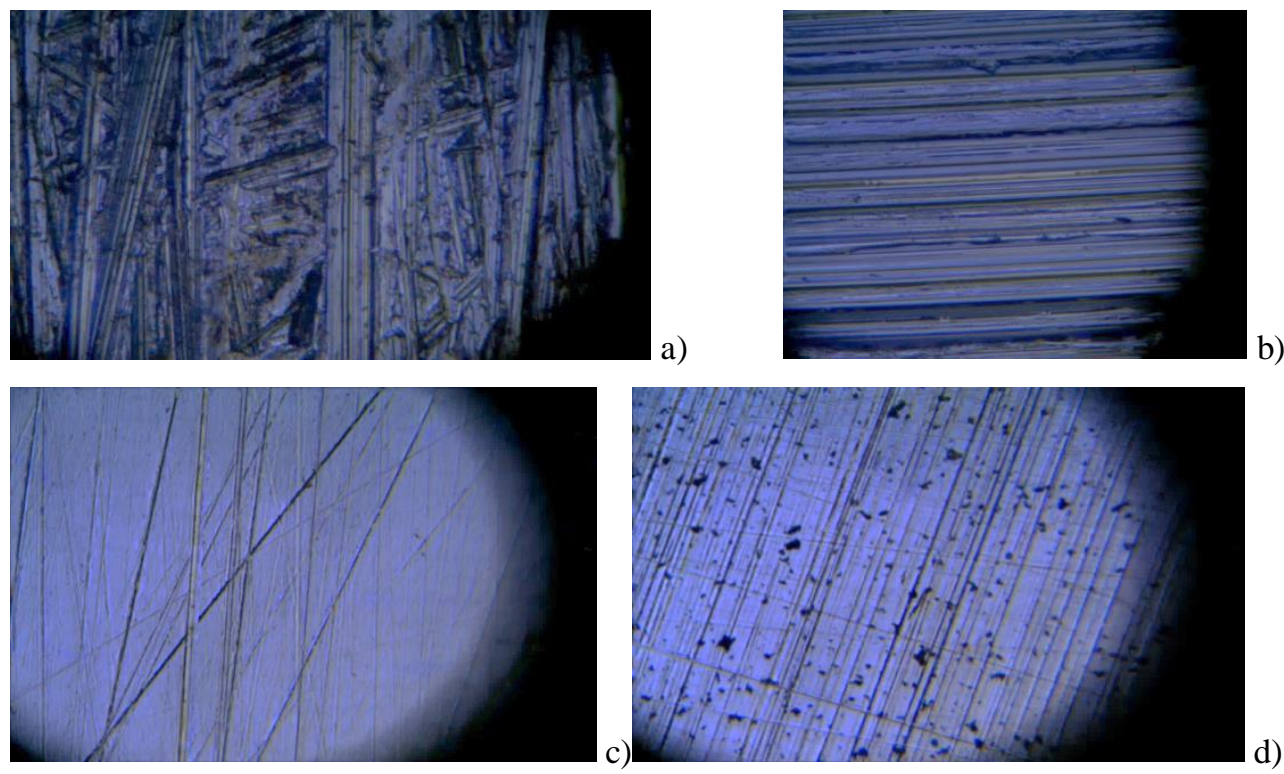

Fig. 2. Microphotographs of the surface [x 1200]: a) worn; b) after fine turning; c) after preliminary refinement; d) after final refinement.

Smoothing is carried out very evenly at the end of the process because cutting contour becomes very even which is proved by photographs taken of initial (worn) surface and finally refined one (refer to fig. 2 a, b) which were obtained using microinterferometer. Thus, accepted hypothesis proposed by I.V. Grebenshchikov with made additions allows explaining the physical and chemical essence of the processes that occur during refinement of details contact surfaces of isolation valves in order to ensure required tightness of such assemblies. It is necessary to pay attention (refer to fig. 2) on presence of black streaks and clots on the processed surface formed by usage of abrasive grain at the final refining 
operation and poor flushing of the paste residue. Depth of such residual streaks at the final refining operation can be determined from equation

$$
\frac{h}{\rho}=0.5,
$$

where $\mathrm{h}$ is grain penetration depth;

$\rho$ is radius of top of the grain rounding.

After measuring geometric dimensions of the grain used in the last operation which are equal to $3 \times 5 \mathrm{~mm}$ as well as the radius of top of this grain rounding which is on average equal to $\rho \approx 0.0001 \mathrm{~mm}$ resulting value of cavities after refining operation is equal to $\mathrm{h}=0.1 \times 0.5=0.05 \mu \mathrm{m}$ that is quite suitable for our version of technology for processing contact precision large-sized details of isolation valves.

\section{Conclusions}

1. It has been revealed that a complex of factors simultaneously acting on refinement takes place during refining precision surfaces of isolation valves, namely, cutting by abrasive grains, plastic flow of metal and chemical effect of surfactants.

2. It is necessary to conduct additional studies to determine degree of influence of each of them on refining process because refinement has significant effect on choices of processing modes and required composition of abrasive material.

The reported study was funded by RFBR according to the research project №19-08-01241a. The authors declare that there is no conflict of interest regarding the publication of this paper. This research work was supported by the Academic Excellence Project 5-100 proposed by Peter the Great St. Petersburg Polytechnic University.

\section{References}

1. Hasçalik, U. Çaydaş, Journal of Materials Processing Technology, 190(1-3), 173-180 (2007) DOI: 10.1016/j.jmatprotec.2007.02.048

2. N.A. Zhuravskii, D.É. Polesskii, I.V. Prokhorov, Journal of Engineering Physics and Thermophysics, 75, 390-395 (2002)

3. V. Kukhar, E. Balalayeva, A.Prysiazhnyi, O. Vasylevskyi, I. Marchenko, MATEC Web of Conferences, 178, 02003 (2018) DOI: 10.1051/matecconf/201817802003

4. V.V. Kukhar, A.V. Grushko, I.V. Vishtak, Solid State Phenomena, 284, 408-415 (2018) DOI: 10.4028/www.scientific.net/SSP.284.408

5. V. Artiukh, V. Mazur, Y. Sahirov, N. Kapustina, Advances in Intelligent Systems and Computing, 1115, 950-962 (2020) DOI: https://doi.org/10.1007/978-3-030-379162_94

6. A.N. Levandovskiy, B.E. Melnikov, A.A. Shamkin, Magazine of Civil Engineering, 1, 3-22 (2017) DOI: 10.18720/MCE.69.1

7. G. Gou, P. Xie, Z. Wen, Y. Ding, W. Yang, Advanced Materials Research, 221, 123128 (2011) DOI: 10.4028/www.scientific.net/AMR.221.123

8. A.M. Khanov, K.R. Muratov, R.A. Muratov, E.A. Gashev, Modern Applied Science, 9(6), 278-286 (2015) DOI: 10.5539/mas.v9n6p278 
9. S. Kargin, V. Artiukh, V. Mazur, D. Silka, N. Meller, Advances in Intelligent Systems and Computing, 982, 818-824 (2020) DOI: https://doi.org/10.1007/978-3-030-197568_78

10. V.V. Maksarov, A.I. Keksin, IOP Conference Series: Earth and Environmental Science, 194(6), 062016 (2018) DOI: 10.1088/1755-1315/194/6/062016

11. V. Nikitchenko, V. Artiukh, D. Shevchenko, A. Larionov, I. Zubareva, Advances in Intelligent Systems and Computing, 983, 496-510 (2019) DOI: https://doi.org/10.1007/978-3-030-19868-8_49

12. S.A.R. Junior, J.L. Ferracane, A.D. Bona, Dental Materials, 25(4), 442-451 (2009) DOI: 10.1016/j.dental.2008.09.009

13. A.I. Blesman, D.V. Postnikov, G.M. Seropyan, E.A. Tkachenko, A.A. Teplouhov, D.A. Polonyankin, IOP Conference Series: Materials Science and Engineering, 012007 (2016) DOI: 10.1088/1757-899X/110/1/012007

14. P.O. Maruschak, S.V. Panin, I.M. Zakiev, M.A. Poltaranin, A.L. Sotnikov, Engineering Failure Analysis, 59, 69-78 (2016)

15. Y.A. Samoilovich, Steel in Translation, 48(3), 189-196 (2018) DOI: 10.3103/S0967091218030105

16. X.Q.Li, H.R.Dong, Y.S.Zhang, D.S. Li, Suxing Gongcheng Xuebao, 25(5), 87-98 (2018) DOI: 10.3969/j.issn.1007-2012.2018.05.012

17. D. Usvyat, Journal of Chemical Physics, 143(10), 104704 (2015) DOI: 10.1063/1.4930851

18. V. Anishchenko, V. Kukhar, V. Artiukh, O. Arkhipova, MATEC Web of Conferences, 239, 06007 (2018) DOI: 10.1051/matecconf/201823906007

19. D.B. Efremov, A.A. Gerasimova, S.M. Gorbatyuk, N.A. Chichenev, CIS Iron and Steel Review, 18, 30-34 (2019)

20. D. Kitaeva, G. Kodzhaspirov, Y. Rudaev, Proceeding of the 25th International Conference on Metallurgy and Materials METAL,1426-1431 (2016) 